Syntax Literate: Jurnal Ilmiah Indonesia p-ISSN: 2541-0849

e-ISSN: 2548-1398

Vol. 5, No. 7, Juli 2020

\title{
TINGKAT PENGETAHUAN IBU HAMIL DENGAN PENGGUNAAN TABLET KALSIUM LAKTAT PADA IBU HAMIL
}

\section{Lina Siti Nuryawati}

Sekolah Tinggi Kesehatan Yayasan Pendidikan Imam Bonjol (STIKes YPIB) Majalengka

Email: linasn20@gmail.com

\section{Abstract}

The need for calcium increases during pregnancy, in addition to being important for the health of the bones of the mother and fetus, it is also known that adequate calcium intake can reduce the incidence of hypertension in pregnancy and prevent premature birth. This study aims to determine the relationship of knowledge with the use of calcium lactate tablets in pregnant women at UPTD Puskesmas Cikijing Majalengka Regency in 2019. This type of research uses quantitative research with cross sectional approach. The sample in this study was 91 pregnant women in UPTD Cikijing Community Health Center in Majalengka with accidental sampling technique. The research was conducted on April 15-June 10, 2019. Data analysis used univariate analysis with frequency distribution and bivariate analysis with chi square test. The results showed that more than half (69.2\%) of pregnant women who did not use calcium lactate tablets and less than half (33.0\%) of pregnant women lacked knowledge. There is a relationship of knowledge with the use of calcium lactate tablets in pregnant women in UPTD Cikijing Community Health Center in Majalengka in 2019 ( $\square$ value =0.014). Health workers should provide counseling about calcium lactate tablets to pregnant women to prevent reducing the risk of preeclampsia and prevent preterm birth and motivate pregnant women to consume calcium lactate during pregnancy according to the dosage and instructions, especially for pregnant women who often complain of cramps or tingling and at risk of osteoporosis.

Keywords: Knowledge; pregnant women; calcium lactate tablets

\begin{abstract}
Abstrak
Kebutuhan kalsium meningkat selama kehamilan, selain penting bagi kesehatan tulang ibu dan janin, diketahui pula asupan kalsium yang cukup dapat mengurangi kejadian hipertensi dalam kehamilan dan mencegah kelahiran prematur. Penelitian ini bertujuan untuk mengetahui hubungan pengetahuan dengan penggunaan tablet kalsium laktat pada ibu hamil di UPTD Puskesmas Cikijing Kabupaten Majalengka Tahun 2019. Jenis penelitian ini menggunakan penelitian kuantitatif dengan pendekatan cross sectional. Sampel dalam penelitian ini adalah ibu hamil di UPTD Puskesmas Cikijing Kabupaten Majalengka sebanyak 91 orang dengan teknik accidental sampling. Penelitiannya dilakukan pada tanggal 15 April-10 Juni 2019. Analisis datanya menggunakan analisis univariat dengan distribusi frekuensi dan analisis bivariat dengan uji chi square. Hasil penelitian menunjukkan bahwa lebih
\end{abstract}


dari setengah $(69,2 \%)$ ibu hamil yang tidak menggunakan tablet kalsium laktat dan kurang dari setengah $(33,0 \%)$ ibu hamil berpengetahuan kurang. Ada hubungan pengetahuan dengan penggunaan tablet kalsium laktat pada ibu hamil di UPTD Puskesmas Cikijing Kabupaten Majalengka Tahun 2019 ( $\rho$ value $=0,014)$. Petugas kesehatan agar memberikan penyuluhan tentang tablet kalsium laktat pada ibu hamil guna mencegah mengurangi risiko preeklampsia dan mencegah kelahiran prematur serta memotivasi ibu hamil untuk mengkonsumsi kalsium laktat selama kehamilan sesuai dengan dosis dan petunjuk terutama bagi ibu hamil yang sering mengeluh keram atau kesemutan serta berisiko osteoporosis.

Kata kunci: Pengetahuan; ibu hamil; tablet kalsium laktat.

\section{Pendahuluan}

Keberhasilan upaya kesehatan ibu, di antaranya dapat dilihat dari indikator Angka Kematian Ibu (AKI). AKI adalah jumlah kematian ibu selama masa kehamilan, persalinan dan nifas yang disebabkan oleh kehamilan, persalinan, dan nifas atau pengelolaannya tetapi bukan karena sebab-sebab lain seperti kecelakaan atau terjatuh di setiap 100. 000 kelahiran hidup (Kemenkes, 2017).

Kematian ibu di Indonesia didominasi oleh penyebab utama yaitu hipertensi dalam kehamilan dan perdarahan. Hypertensi dalam kehamilan menurut Siti Bandiyah 2019 dalam Sutiati Bardja 2017 merupakan peningkatan sistolik sebesar $30 \mathrm{mmHg}$ atau diastolik sebesar $15 \mathrm{mmHg}$ di atas nilai dasar tekanan darah (Bardja, 2017). Asupan kalsium yang cukup dapat mengurangi kejadian hipertensi selama kehamilan, mengurangi risiko preeklampsia dan mencegah kelahiran prematur. Dan sangat penting bagi kesehatan tulang ibu dan janin, ini yang membuat kebutuhan kalsium meningkat selama kehamilan (Camargo et al., 2013).

Selama masa kehamilan, janin di dalam kandungan akan membutuhkan asupan kalsium untuk pembentukan tulang dan gigi kuat. Kalsium juga penting untuk menjaga detak jantung ibu hamil selalu stabil dan saraf serta otot berfungsi dengan baik. Saat hamil, bayi yang sedang berkembang membutuhkan kalsium untuk membentuk tulang dan gigi yang kuat; mengembangkan jantung, saraf, dan otot yang kuat; dan untuk mengembangkan irama jantung dan kemampuan pembekuan darah yang normal (Camargo et al., 2013).

Wanita hamil di negara berkembang umumnya memiliki asupan kalsium yang rendah. Penelitian yang dilakukan di Kamerun menunjukkan sebanyak 94, $6 \%$ ibu hamil memiliki asupan kalsium yang inadekuat. Berdasarkan penelitian di daerah selatanThailand, tampak bahwa sebanyak 55 persen ibu hamil memiliki asupan kalsium inadekuat dengan rata-rata asupan kalsium sebesar 493, 2mg/hari. 6 Penelitian Sacco et al. di Peru menunjukkan bahwa prevalensi ibu hamil yangmemiliki asupan kalsium inadekuat sebesar 86\% (Agueh et al., 2015).

World Health Organization (WHO) telah merekomendasikan suplementasi kalsium 1500-2000 mg/hari pada populasi dengan asupan kalsium rendah sebagai bagian dari antenatal care (ANC) sebagai pencegahan preeklampsia pada ibu hamil, 
terutama pada ibu hamil yang memiliki risiko tinggi hipertensi (WHO, 2013). Sesuai dengan rekomendasi WHO, di Indonesia telah ada anjuran suplementasi kalsium sebesar 1500-2000 mg/hari pada area dengan asupan kalsium rendah sebagai pencegahan preeklampsia sebagaimana tertuang dalam Buku Saku Pelayanan Kesehatan Ibu di Fasilitas Kesehatan Dasar dan Rujukan (Kemenkes, WHO, POGI, IBI 2013). Meskipun demikian, anjuran ini belum menjadi program wajib Kementrian Kesehatan (Kemenkes) RI. Pelaksanaan suplementasi kalsium di puskesmas tidak selalu sama dalam hal waktu dan jumlah pemberian suplemen kalsium. Kepatuhan ibu hamil mengonsumsi suplemen selama kehamilan menjadi salah satu tantangan yang paling sering ditemui dalam mencapai pelaksanaan program suplementasi mikronutrien yang efektif (Sanghvi, Harvey, \& Wainwright, 2010); (Martin et al., 2017).

Pendidikan gizi dan konseling selama kehamilan digunakan secara luas untuk memperbaiki status gizi ibu hamil. Systematic review dan meta-analysis mengenai pengaruh pendidikan gizi dan konseling selama kehamilan menunjukkan adanya peningkatan outcome kesehatan ibu dan bayi, termasuk meningkatnya kepatuhan mengonsumsi suplemen yang dianjurkan dan peningkatan asupan gizi ibu hamil (Olude, 2012). Petugas kesehatan berperan dalam pendidikan gizi dan konseling ibu hamil kaitannya dalam meningkatkan pengetahuan ibu (Camargo et al., 2013) (Agueh et al., 2015). Konseling mengenai suplementasi kalsium dan Hipertensi Dalam Kehamilan (HDK) yang dilakukan dengan baik oleh petugas diharapkan dapat meningkatkan kepatuhan ibu hamil dalam mengonsumsi suplemen kalsium. Kemudian dapat memenuhi kebutuhan kalsium ibu hamil dan dapat mengurangi risiko terjadinya Hipertensi Dalam Kehamilan.

Berdasarkan data Dinas Kesehatan Kabupaten Majalengka jumlah ibu hamil di Kabupaten Majalengka pada tahun 2017 sebanyak 21.092 orang dan paling banyak jumlah ibu hamil terdapat di UPTD Puskesmas Cikijing yaitu sebanyak 1.074 orang (Majalengka, 2018). Namun untuk data mengenai jumlah konsumsi kalsium laktat belum ada hal ini dikarenakan pelaksanaan suplementasi kalsium di puskesmas tidak selalu sama dan belum menjadi program wajib dari pemerintah.

Tablet kalsium laktat mengandung kalsium laktat, C6H10CaO6. 5H2O. Kebutuhan kalsium meningkat selama kehamilan, selain penting bagi kesehatan tulang ibu dan janin, diketahui pula asupan kalsium yang cukup dapat mengurangi kejadian HDK (hipertensi dalam kehamilan), suplementasi kalsium dapat mengurangi risiko preeklampsia (gangguan kehamilan yang ditibui oleh tekanan darah tinggi) dan mencegah kelahiran premature (Camargo et al., 2013).

Kalsium tidak dapat dihasilkan oleh tubuh sehingga kebutuhan kalsium harus dipenuhi dari luar, yaitu dari makanan dan suplemen (jika dibutuhkan). Saat ibu hamil kurang bisa memenuhi kebutuhan kalsium untuk janin, janin akan mengambil kalsium dari tulang ibu. Sehingga, kurangnya asupan kalsium dapat mengganggu kesehatan tulang ibu sendiri (Jannah, 2015).

Untuk mencegah risiko pada kehamilan tersebut, maka ibu hamil perlu mengetahui dengan baik tentang kegunaan kalsium laktat sehingga ibu hamil dapat 
mengkonsumsi kalsium laktat selama kehamilan. Kalsium laktat adalah obat yang berfungsi untuk mencegah serta mengatasi kadar kalsium yang rendah di dalam darah atau hipokalsemia. Obat ini bisa ditimbulkan untuk memenuhi kebutuhan kalsium bagi ibu hamil yang tidak mendapatkan kalsium yang cukup dari makanan (Marmi, 2015).

Pengetahuan adalah hasil dari tahu, dan terjadi setelah orang melakukan penginderaan terhadap suatu objek tertentu. Penginderaan itu terjadi melalui panca indera manusia yakni indera penglihatan, pendengaran, penciuman, rasa dan raba. Sebagian besar penginderaan manusia diperoleh melalui mata dan telinga. Pengetahuan kognitif merupakan domain yang sangat penting dalam membentuk tindakan seseorang (overt behavior) (Notoatmodjo, 2015).

Berbagai studi tentang evaluasi program suplementasi menunjukkan bahwa kepatuhan ibu hamil mengonsumsi suplemen selama kehamilan menjadi salah satu tantangan yang paling sering ditemui dalam mencapai pelaksanaan program suplementasi yang efektif pada ibu hamil. Selama ini informasi mengenai faktor-faktor yang berhubungan dengan kepatuhan konsumsi suplemen kalsium masih terbatas dan belum banyak informasi mengenai tingkat kecukupan kalsium pada ibu hamil di Indonesia (Purnasari, Briawan, \& Dwiriani, 2016).

Hasil penelitian ini sejalan dengan penelitian Purnasari di Kabupaten Jember menunjukkan bahwa salah satu faktor yang mempengaruhinya adalah pengetahuan yang kurang ( $\rho=0,011)$. Juga hasil penelitian Ivan (2016) di RS Panti Rapih Yogyakarta yang menyatakan bahwa ada hubungan antara pengetahuan yang kurang dengan konsumsi kalsium pada ibu hamil $(\rho=0,001)$. Demikian juga hasil penelitian Indriyani (2017) di Puskesmas Sungai Jingah Banjarmasin ada hubungan antara pengetahuan ibu hamil dengan penggunaan tablet kalsium laktat $(\rho=0,024)$ (Purnasari et al., 2016).

Berdasarkan studi pendahuluan yang dilakukan pada 10 responden di UPTD Puskesmas Cikijing yang berpengetahuan baik sebanyak 2 responden (20\%), yang berpengetahuan cukup 4 responden (40\%), dan yang berpengetahuan kurang 4 responden $(40 \%)$.

Berdasarkan uraian latar belakang dan hasil penelitian terdahulu yang masih menunjukkan perbedaan, maka penulis merasa tertarik untuk meneliti kembali tentang "Hubungan Pengetahuan dengan Penggunaan Tablet Kalsium Laktat Pada Ibu Hamil di UPTD Puskesmas Cikijing Kabupaten Majalengka Tahun 2019.”

\section{Metode Penelitian}

Jenis penelitian ini menggunakan penelitian kuantitatif dengan pendekatan cross sectional. Sampel pada penelitian ini adalah ibu hamil di UPTD Puskesmas Cikijing Kabupaten Majalengka yang berjumlah 91 responden dengan menggunakan metode accidental sampling. Lokasi penelitian telah dilakukan di UPTD Puskesmas Cikijing Kabupaten Majalengka pada tanggal 15 April sampai dengan 10 Juni 2019. Instrumen pada penelitian ini menggunakan data primer yaitu kuesioner dan lembar observasi. variabel penelitian menggunakan distribusi frekuensi dan Uji yang dipakai adalah chisquare dengan batas kemaknaan $95 \%$. 


\section{Hasil Penelitian}

\section{A. Hasil Penelitian}

1. Analisis Univariat

a. Gambaran Penggunaan Tablet Kalsium Laktat pada Ibu Hamil di UPTD Puskesmas Cikijing Kabupaten Majalengka Tahun 2019

Tabel 1 Distribusi Frekuensi Penggunaan Tablet Kalsium Laktat pada Ibu Hamil di UPTD Puskesmas Cikijing Kabupaten Majalengka Tahun 2019

\begin{tabular}{|c|c|c|c|}
\hline No & $\begin{array}{c}\text { Penggunaan Tablet } \\
\text { Kalsium Laktat pada } \\
\text { Ibu Hamil }\end{array}$ & Frekuensi & $\%$ \\
\hline 1 & Tidak & 63 & 69.2 \\
\hline 2 & $\mathrm{Ya}$ & 28 & 30.8 \\
\hline & Jumlah & 91 & 100.0 \\
\hline
\end{tabular}

Berdasarkan tabel 1 diketahui bahwa ibu hamil yang tidak menggunakan tablet kalsium laktat sebanyak 63 orang $(69,2 \%)$ dan yang menggunakan tablet kalsium laktat sebanyak 28 orang $(30,8 \%)$. Hal ini menunjukkan bahwa lebih dari setengah (69,2\%) ibu hamil di UPTD Puskesmas Cikijing Kabupaten Majalengka Tahun 2019 yang tidak menggunakan tablet kalsium laktat.

b. Gambaran Pengetahuan Ibu Hamil di UPTD Puskesmas Cikijing Kabupaten Majalengka Tahun 2019

Tabel 2 Distribusi Frekuensi Pengetahuan Ibu Hamil di UPTD Puskesmas Cikijing Kabupaten Majalengka Tahun 2019

\begin{tabular}{clcc}
\hline No & \multicolumn{1}{c}{$\begin{array}{c}\text { Pengetahuan } \\
\text { Ibu Hamil }\end{array}$} & Frekuensi & \% \\
\hline 1 & Kurang & 30 & 33.0 \\
\hline 2 & Cukup & 37 & 40.7 \\
\hline 3 & Baik & 24 & 26.4 \\
\hline \multicolumn{2}{r}{ Jumlah } & $\mathbf{9 1}$ & $\mathbf{1 0 0 . 0}$ \\
\hline
\end{tabular}

Berdasarkan tabel 2 diketahui bahwa ibu hamil yang berpengetahuan kurang sebanyak 30 orang $(33,0 \%)$, yang berpengetahuan cukup sebanyak 37 orang $(40,7 \%)$ dan berpengetahuan baik sebanyak 24 orang $(26,4 \%)$. Hal ini menunjukkan bahwa kurang dari setengah $(33,0 \%)$ ibu hamil di UPTD Puskesmas Cikijing Kabupaten Majalengka Tahun 2019 berpengetahuan kurang.

2. Analisis Bivariat

a. Hubungan Pengetahuan dengan Penggunaan Tablet Kalsium Laktat pada Ibu Hamil di UPTD Puskesmas Cikijing Kabupaten Majalengka Tahun 2019 
Tabel 3 Distribusi Proporsi Hubungan Pengetahuan dengan

Penggunaan Tablet Kalsium Laktat pada Ibu Hamil di UPTD

Puskesmas Cikijing Kabupaten Majalengka Tahun 2019

Penggunaan Tablet

\begin{tabular}{|c|c|c|c|c|c|c|c|c|}
\hline \multirow{3}{*}{ No } & \multirow{3}{*}{$\begin{array}{c}\text { Pengetahuan } \\
\text { Ibu Hamil }\end{array}$} & \multicolumn{4}{|c|}{ Kalsium Laktat } & \multicolumn{2}{|c|}{ Jumlah } & \multirow[t]{2}{*}{ ovalue } \\
\hline & & \multicolumn{2}{|c|}{ Tidak } & \multicolumn{2}{|c|}{ Ya } & & & \\
\hline & & $\mathbf{n}$ & $\%$ & $\mathbf{n}$ & $\%$ & n & $\%$ & \multirow{5}{*}{0.014} \\
\hline 1 & Kurang & 24 & 80,0 & 6 & 20,0 & 30 & 100 & \\
\hline 2 & Cukup & 28 & 75,7 & 9 & 24,3 & 37 & 100 & \\
\hline 3 & Baik & 11 & 45,8 & 13 & 54,2 & 24 & 100 & \\
\hline & Jumlah & 63 & 69,2 & 28 & 30,8 & 91 & 100 & \\
\hline
\end{tabular}

Berdasarkan tabel 3 diketahui bahwa ibu hamil yang tidak menggunakan tablet kalsium laktat dengan pengetahuan kurang sebanyak 24 orang $(80,0 \%)$, ibu hamil yang tidak menggunakan tablet kalsium laktat dengan pengetahuan cukup sebanyak 28 orang $(75,7 \%)$, sedangkan ibu hamil yang tidak menggunakan tablet kalsium laktat dengan pengetahuan baik sebanyak 11 orang $(45,8 \%)$. Hal ini menunjukkan bahwa proporsi ibu hamil yang tidak menggunakan tablet kalsium laktat lebih banyak terdapat pada ibu hamil yang berpengetahuan kurang dibanding ibu hamil yang berpengetahuan cukup atau baik.

Berdasarkan hasil uji statistik, diperoleh $\rho$ value $=0,014$ yang artinya $\rho$ value $<\alpha(0,05)$ sehingga hipotesis nol ditolak. Dengan demikian maka ada hubungan pengetahuan dengan penggunaan tablet kalsium laktat pada ibu hamil di UPTD Puskesmas Cikijing Kabupaten Majalengka Tahun 2019.

\section{B. Pembahasan}

1. Gambaran Penggunaan Tablet Kalsium Laktat pada Ibu Hamil di UPTD Puskesmas Cikijing Kabupaten Majalengka Tahun 2019

Berdasarkan hasil penelitian menunjukkan bahwa lebih dari setengah $(69,2 \%)$ ibu hamil di UPTD Puskesmas Cikijing Kabupaten Majalengka Tahun 2019 yang tidak menggunakan tablet kalsium laktat. Hasil observasi di lapangan masih banyak ibu hamil yang tidak meminum tablet kalsium laktat selama kehamilan hal ini dikarenakan ibu belum tahu bahwa ibu hamil memerlukan kalsium dan salah satu tablet yang dapat menambah kalsium pada ibu hamil adalah tablet kalsium laktat, dampak dari kekurangan kalsium selama kehamilan yaitu akan membuat bayinya memiliki tulang yang rapuh, berisiko preeklampsia, kelahiran prematur dan selama kehamilan bayi akan menyerap asupan kalsium dari tulang ibu membuat ibu mengalami risiko keropos tulang atau osteoporosis.

Hasil penelitian ini lebih tinggi dibanding dengan penelitian (Ivan, 2016) di RS Panti Rapih Yogyakarta ibu hamil yang tidak mengkonsumsi kalsium 
sebesar 55\% dan lebih rendah dibanding hasil penelitian (Indriyani, 2017) di Puskesmas Sungai Jingah Banjarmasin bahwa ibu hamil yang yang tidak mengkonsumsi tablet kalsium laktat hanya $70 \%$.

Kalsium laktat adalah obat yang berfungsi untuk mencegah serta mengatasi kadar kalsium yang rendah di dalam darah atau hipokalsemia. Kalsium laktat ini bisa ditimbulkan untuk memenuhi kebutuhan kalsium bagi orang yang tidak mendapatkan kalsium yang cukup dari makanan (Marmi, 2015). Kalsium laktat adalah obat yang berperan dalam memenuhi kebutuhan tubuh akan kalsium, karena kekurangan kalsium dalam tubuh dapat menyebabkan berbagai masalah dan gangguan tubuh (Rukiyah \& Yulianti, 2014).

Kalsium laktat ini juga bisa digunakan bagi orang yang mengalami gangguan kesehatan tertentu yang diakibatkan oleh kekurangan kalsium, seperti osteoporosis, rakitis, gangguan kelenjar paratiroid dan penyakit otot tertentu (latent tetany) (Varney, Kriebs, \& Gegor, 2014). Kalsium laktat sangat penting untuk wanita hamil. Kadar kalsium ibu memengaruhi kepadatan mineral tulang janin dan bayi yang baru lahir. Ibu yang kekurangan kalsium akan membuat bayinya memiliki tulang yang rapuh. Resiko lainnya yaitu bayi akan menyerap asupan kalsium yang dari tulang ibu sehingga mengurangi kepadatan tulang ibu, kalsium yang diserap bayi dari tulang ibu membuat ibu mengalami risiko keropos tulang atau osteoporosis, meningkatkan risiko hipertensi dan melahirkan prematur, mengganggu proses pembekuan darah dan sekresi hormon dan ibu akan mengalami hipokalsemia yaitu kondisi kekurangan kalsium di dalam aliran darah yang bisa berkaibat pada kelahiran prematur dan kurangnya berat badan pada bayi (Cunningham, 2014).

Upaya untuk meningkatkan penggunaan tablet kalsium laktat pada ibu hamil maka petugas kesehatan agar memberikan penyuluhan tentang tablet kalsium laktat pada ibu hamil terutama pada ibu hamil yang mengeluh sering keram atau sering merasa kesemutan dan berisiko osteoporosis, dan bagi ibu hamil lainnya sebagai pemenuhan kebutuhan kalsium selama kehamilan untuk mencegah mengurangi risiko preeklampsia dan mencegah kelahiran prematur. Bagi ibu hamil agar berkonsultasi kepada bidan atau petugas kesehatan jika mengalami keluhan sering keram atau sering merasa kesemutan dan mengkonsumsi tablet kalsium laktat untuk mengatasi kekurangan kalsium selama kehamilan jika ibu hamil berisiko osteoporosis.

2. Gambaran Pengetahuan Ibu Hamil di UPTD Puskesmas Cikijing Kabupaten Majalengka Tahun 2019

Berdasarkan hasil penelitian menunjukkan bahwa kurang dari setengah $(33,0 \%)$ ibu hamil di UPTD Puskesmas Cikijing Kabupaten Majalengka Tahun 2019 berpengetahuan kurang. Hasil observasi di lapangan masih terdapat ibu yang berpengetahuan kurang hal ini dikarenakan ibu belum terpapar informasi tentang tablet kalsium laktat baik dari bidan atau dari media informasi, 
akibatnya ibu hamil kurang memahami dengan baik tentang tablet kalsium laktat.

Hasil penelitian ini lebih rendah dibanding penelitian (Purnasari et al., 2016) di Kabupaten Jember menunjukkan bahwa persentase ibu hamil yang yang berpengetahuan kurang sebesar 65\% juga hasil penelitian (Ivan, 2016) di RS Panti Rapih Yogyakarta ibu hamil yang pengetahuannya kurang sebesar $45 \%$.

Pengetahuan adalah merupakan hasil mengingat suatu hal, termasuk mengingat kembali kejadian yang pernah dialami baik secara sengaja maupun tidak sengaja dan ini terjadi setelah orang malakukan kontak atau pengamatan terhadap suatu obyek tertentu. Pengetahuan merupakan justified true believe. Seorang individu membenarkan (justifies) kebenaran atas kepercayaannya berdasarkan observasinya mengenai dunia. Dalam definisi ini, pengetahuan merupakan konstruksi dari kenyataan, dibandingkan sesuatu yang benar secara abstrak. Penciptaaan pengetahuan melibatkan perasaan dan sistem kepercayaan (belief sistems) dimana perasaan atau sistem kepercayaan itu bisa tidak disadari (Mubarak, 2014).

Tablet kalsium laktat mengandung kalsium laktat, C6H10CaO6. 5H2O. Kebutuhan kalsium meningkat selama kehamilan, selain penting bagi kesehatan tulang ibu dan janin, diketahui pula asupan kalsium yang cukup dapat mengurangi kejadian HDK (hipertensi dalam kehamilan), suplementasi kalsium dapat mengurangi risiko preeklampsia (gangguan kehamilan yang ditibui oleh tekanan darah tinggi) dan mencegah kelahiran premature (Camargo et al., 2013).

Kalsium tidak dapat dihasilkan oleh tubuh sehingga kebutuhan kalsium harus dipenuhi dari luar, yaitu dari makanan dan suplemen (jika dibutuhkan). Saat ibu hamil kurang bisa memenuhi kebutuhan kalsium untuk janin, janin akan mengambil kalsium dari tulang ibu. Sehingga, kurangnya asupan kalsium dapat mengganggu kesehatan tulang ibu sendiri (Jannah, 2015)

Upaya untuk meningkatkan pengetahuan ibu hamil tentang tablet kalsium laktat yaitu petugas kesehatan agar memberikan informasi atau penyuluhan kepada ibu hamil ketika berkunjung memeriksakan kehamilan terutama pada ibu hamil yang mengeluh sering keram dan sering kesemutan atau berisiko osteoporosis yang merupakan tanda ibu kekurangan kalsium dapat diatasi dengan mengkonsumsi kalisum laktat selama kehamilan. Bagi ibu hamil agar melakukan pemeriksaan kehamilan dengan teratur untuk mendapatkan informasi penting dari petugas kesehatan dan berkonsultasi jika ibu berisiko mengalami osteoporosis.

3. Hubungan Pengetahuan dengan Penggunaan Tablet Kalsium Laktat pada Ibu Hamil di UPTD Puskesmas Cikijing Kabupaten Majalengka Tahun 2019

Berdasarkan hasil penelitian menunjukkan bahwa ada hubungan pengetahuan dengan penggunaan tablet kalsium laktat pada ibu hamil di UPTD 
Puskesmas Cikijing Kabupaten Majalengka Tahun 2019 ( $\rho$ value = 0,014). Adanya hubungan hal ini dikarenakan semakin baik pengetahuan dan pemahaman ibu tentang tablet kalsium laktat akan melahirkan sikap dan pada akhirnya mendorong perilaku yang baik yaitu penggunaan tablet kalsium laktat oleh ibu hamil.

Hasil penelitian ini sejalan dengan penelitian (Purnasari et al., 2016) di Kabupaten Jember menunjukkan bahwa salah satu faktor yang mempengaruhinya adalah pengetahuan yang kurang $(\rho=0,011)$. Juga hasil penelitian (Ivan, 2016) di RS Panti Rapih Yogyakarta yang menyatakan bahwa ada hubungan antara pengetahuan yang kurang dengan konsumsi kalsium pada ibu hamil ( $\rho=0,001)$. Demikian juga hasil penelitian Indriyani (2017) di Puskesmas Sungai Jingah Banjarmasin ada hubungan antara pengetahuan ibu hamil dengan penggunaan tablet kalsium laktat $(\rho=0,024)$.

Hasil penelitian ini sejalan dengan teori bahwa pengetahuan merupakan salah satu hal yang mempengaruhi perilaku. Lebih spesifik, faktor biologis, pengalaman seseorang mengenai makanan dan faktor lingkungan dapat mempengaruhi pilihan makan dan praktik makan seseorang. Proses psikologis yang kuat yang meliputi persepsi, kepercayaan, nilai, dan sikap merupakan kunci dari apa yang orang lakukan. Sehingga, pengetahuan ibu hamil mengenai kecakupan kalsium dan suplementasi kalsium akan mempengaruhi apa yang akan dilakukan yang biasa disebut determinan perilaku. Dalam konteks inizi, hal ini berarti determinan yang dapat diubah adalah pengetahuan sehingga menghasilkan tindakan yang nyata dalam masalah kesehatan (Notoatmodjo, 2015).

Hasil penelitian ini sejalan dengan teori bahwa untuk mencegah risiko pada kehamilan tersebut, maka ibu hamil perlu mengetahui dengan baik tentang kegunaan kalsium laktat sehingga ibu hamil dapat mengkonsumsi kalsium laktat selama kehamilan. Kalsium laktat adalah obat yang berfungsi untuk mencegah serta mengatasi kadar kalsium yang rendah di dalam darah atau hipokalsemia. Obat ini bisa ditimbulkan untuk memenuhi kebutuhan kalsium bagi ibu hamil yang tidak mendapatkan kalsium yang cukup dari makanan (Marmi, 2015).

Pengetahuan terbukti dapat mempengaruhi penggunaan tablet kalsium laktat pada ibu hamil maka dari itu perlunya petugas kesehatan melakukan penyuluhan pada ibu hamil tentang kalsium laktat serta meningkatkan upaya pemenuhan kalsium pada ibu hamil guna mencegah mengurangi risiko preeklampsia dan mencegah kelahiran prematur salah satunya dengan mengkonsumsi kalsium laktat. Bagi ibu hamil untuk mencegah risiko preeklampsia dan mencegah kelahiran prematur serta pemenuhan unsur kalsium selama kehamilan maka ibu hamil dapat mengkonsumsi kalsium laktat secara teratur. 
Lina Siti Nuryawati

\section{Kesimpulan}

Lebih dari setengah $(69,2 \%)$ ibu hamil di UPTD Puskesmas Cikijing Kabupaten Majalengka Tahun 2019 yang tidak menggunakan tablet kalsium laktat. Kurang dari setengah (33,0\%) ibu hamil di UPTD Puskesmas Cikijing Kabupaten Majalengka Tahun 2019 berpengetahuan kurang. Ada hubungan pengetahuan dengan penggunaan tablet kalsium laktat pada ibu hamil di UPTD Puskesmas Cikijing Kabupaten Majalengka Tahun 2019 ( $\rho$ value $=0,014)$. 


\section{BIBLIOGRAFI}

Agueh, Victoire Damienne, Tugoué, Madeleine Flore, Sossa, Charles, Métonnou, Clémence, Azandjemè, Colette, Paraiso, Noel Moussiliou, Ouendo, Marius Edgard, Ouédraogo, Laurent T., \& Makoutodé, Michel. (2015). Dietary calcium intake and associated factors among pregnant women in southern Benin in 2014. Food and Nutrition Sciences, 6(11), 945.

Bardja, Sutiati. (2017). Faktor-Faktor Yang Mempengaruhi Terjadinya Hipertensi Dalam Kehamilan Pada Ibu Hamil Di Puskesmas Gunung Jati Tahun 2015. Syntax Literate; Jurnal Ilmiah Indonesia, 2(11), 151-161.

Camargo, Erika Barbosa, Moraes, Luci Fabiane Scheffer, Souza, Celsa Moura, Akutsu, Rita, Barreto, Jorge Maia, da Silva, Edina Mariko Koga, Betrán, Ana Pilar, \& Torloni, Maria Regina. (2013). Survey of calcium supplementation to prevent preeclampsia: the gap between evidence and practice in Brazil. BMC Pregnancy and Childbirth, 13(1), 206.

Cunningham, F. Gary. (2014). Obstetri Williams. Jakarta: EGC.

H, Ivan. (2016). Faktor yang Berhubungan dengan Konsumsi Kalsium pada Ibu Hamil di RS Panti Rapih Yogyakarta.

Indriyani. (2017). Hubungan Tingkat Pendidikan dan Pengetahuan Ibu Hamil dengan Penggunaan Tablet Kalsium Laktat di Puskesmas Sungai Jingah. Jurnal Academy Pharmacy ISFI Ranjarmasin.

Jannah, Nurul. (2015). Buku Ajar Asuhan Kebidanan: Kehamilan. Yogyakarta: CV Andi Ofset.

Kemenkes, R. I. (2017). Profil kesehatan Republik Indonesia tahun 2017. Kementerian Kesehatan RI. Jakarta.

Majalengka, Dinas Kesehatan Kabupaten. (2018). Profil Kesehatan Kabupaten Majalengka tahun 2017.

Marmi, Rahardjo K. (2015). Asuhan neonatus, bayi, balita, dan anak prasekolah. Yogyakarta: Pustaka Pelajar.

Martin, Stephanie L., Seim, Gretchen L., Wawire, Salome, Chapleau, Gina M., Young, Sera L., \& Dickin, Katherine L. (2017). Translating formative research findings into a behaviour change strategy to promote antenatal calcium and iron and folic acid supplementation in western Kenya. Maternal \& Child Nutrition, 13(1).

Mubarak, Wahit Iqbal. (2014). Pengantar Keperawatan Komunitas. Jakarta: CV Sagung seto.

Notoatmodjo, Soekidjo. (2015). Metodologi penelitian kesehatan. Jakarta: rineka cipta. 
Olude, Girard dan. (2012). Determinants Of Compliance To Antenatal Micronutrient Supplementation And Women's Perceptions Of Supplement Use In Rural Nepal. Public Heal Nutr, 13(1), 82-90.

Purnasari, Galih, Briawan, Dodik, \& Dwiriani, Cesilia Meti. (2016). Kepatuhan konsumsi suplemen kalsium serta hubungannya dengan tingkat kecukupan kalsium pada ibu hamil di kabupaten jember. Kesehat Reproduksi, 7(2), 83-93.

Rukiyah, A. Y., \& Yulianti, Lia. (2014). Asuhan Kebidanan Kehamilan Berdasarkan Kurikulum Berbasis Kompetensi. Jakarta Timur: CV. Trans Info Media.

Sanghvi, Tina G., Harvey, Philip W. J., \& Wainwright, Emily. (2010). Maternal ironfolic acid supplementation programs: evidence of impact and implementation. Food and Nutrition Bulletin, 31(2_supp12), S100-S107.

Varney, Helen, Kriebs, Jan M., \& Gegor, Carolyn L. (2014). Buku ajar asuhan kebidanan. Jakarta: Egc, 672-788.

WHO. (2013). Jumlah Ibu Hamil. Retrieved January 12, 2019, from http://www.who.int/en/hypertension 